\title{
The First Golden Minutes of the Extremely-Low-Gestational-Age Neonate: A Gentle Approach
}

\author{
Máximo Vento ${ }^{a}$ Po-Yin Cheung ${ }^{c}$ Marta Aguar ${ }^{b}$ \\ ${ }^{a}$ Neonatal Research Unit, Division of Neonatology, Hospital Universitario La Fe, and ${ }^{\text {b }}$ Research Foundation \\ Hospital La Fe, Valencia, Spain; ' Departments of Paediatrics and Pharmacology, Neonatal Sciences Laboratory, \\ University of Alberta, Edmonton, Alta., Canada
}

\section{Key Words}

Prematurity - Fetal to neonatal transition - Resuscitation • Noninvasive ventilation $\cdot$ Continuous positive airway pressure $\cdot$ Oxidative stress $\cdot$ Inflammation

\begin{abstract}
An increasing body of evidence has revealed that interventions performed during resuscitation of extremely-low-gestational-age neonates (ELGANs) may have a direct influence on the immediate survival and also on long-term morbidity. It has been proposed that interventions in the delivery room and/or hypothermia could trigger changes constitutive of chronic lung disease. New approaches in the first minutes of life using more gentle parameters of intervention are being studied. Thus, titrating inspiratory fraction of oxygen, the use of non-invasive ventilation to reduce trauma to the lung, the use of polyethylene/polyurethane wrapping to avoid hypothermia and delaying cord clamping altogether constitute promising initiatives. The first minutes of life are a valuable window for intervention. However, whilst these practice changes make sense and there are emerging data to support them, further evidence including long-term follow up is needed to definitively change resuscitation procedures in ELGANs.

Copyright $\odot 2008$ S. Karger AG, Basel
\end{abstract}

\section{Morbidity and Mortality of Extremely-Low- Gestational-Age Neonates}

In the last decade, improvement in the survival of infants born with gestational ages at or less than 28 weeks has been widely documented [1-10]: survival of infants born at 24 and 25 weeks' gestation rose from 25 and $50 \%$ in the early 90 s to 40 and $60 \% 10$ years thereafter in Europe and North America, respectively [3-10]. Of note, a similar improvement has also taken place in less developed countries, although the actual mortality rate is higher than that in developed countries [11]. The decrease in mortality rate has been attributed to a constellation of factors, and among them regionalization has been identified as one of the most relevant. Hence, volume of highrisk pregnancies and thus volume of patients admitted into the neonatal intensive care unit (NICU) have been underscored as determining factors to improved perinatal and neonatal care and the increasing survival [12-15]. Moreover, Phibbs et al. [15] predicted that up to $21 \%$ of the deaths of very-low-birth-weight infants in the year 2000 would have been potentially preventable if these infants had been born in a tertiary care regional medical centre. Notwithstanding, improvement in mortality seems not to be correlated to changes in the obstetric practice or neonatal resuscitation of the extremely-lowgestational-age neonates (ELGANs, defined as less than

Prof. Máximo Vento, $\mathrm{PhD}, \mathrm{MD}$

Director of the Neonatal Research Unit, Division of Neonatology

Hospital Universitario La Fe, Avenida de Campanar, 21

ES-46009 Valencia (Spain)

Tel. +34963862 791, Fax +34961973 408, E-Mail maximo.vento@uv.es 
or equal to 28 weeks' gestation). Hence, mortality in the delivery room has not substantially changed in the last decade, representing $15 \%$ of the live-born and $32 \%$ of the total deaths of ELGANs at discharge $[9,10]$. In this regard, perhaps a pro-active or a restrictive approach to antenatal and perinatal treatment of the most immature infants could be a decisive factor to decreasing stillbirth rates and increasing the survival at 22-25 weeks' gestation $[16,17]$. Other factors such as generalized use of prenatal corticosteroids, postnatal use of exogenous surfactant, new modalities of mechanical ventilation, use of inhaled nitric oxide, prevention of streptococcus B infection, and improvement in postnatal care in the NICU, have contributed to lowering mortality among extremely-low-birth-weight (ELBW, defined as less than or equal to $1,000 \mathrm{~g}$ ) infants [6-8].

Interestingly enough, the improvement in mortality has not been paralleled by a decrease in ELGAN morbidity [1-10]. Prevalence of severe complications such as bronchopulmonary dysplasia (BPD), retinopathy of prematurity (ROP), septicaemia, severe intraventricular haemorrhage (IVH) or periventricular leukomalacia (PVL) have not substantially changed despite the increased use of prenatal corticosteroids and surfactant, implementation of indomethacin therapy and reduction in ductus arteriosus ligation, and decreased use of postnatal corticosteroids $[7,8,10,18,19]$.

Fanaroff et al. [8] have indicated that the improvement in ELGAN survival would require determining, disseminating, and applying the best practices available, but also identifying new strategies and interventions. Recent research and clinical evidence suggest that interventions performed in the first minutes after birth may also have long-term consequences in addition to the short-term effects in the rate and quality of survival of ELGANs [2026]. Accordingly, we will discuss basic aspects of postnatal adaptation related to ventilation, oxygenation, and temperature control. In addition, we will suggest how to apply present knowledge and technology in the delivery room (DR) to facilitate ELGAN adaptation to the extrauterine world and improve short- and long-term outcomes.

\section{Ventilation}

\section{Initiation of Respiration in the Fetal to Neonatal}

Transition

To survive after birth, neuronal and muscular components of the respiratory system must be developmentally advanced and functional to generate a rhythm that allows for gas exchange [27]. Hence, mechanisms responsible for this transition require the anatomical development of neuronal populations, onset of rhythmic respiratory neuronal populations, onset of rhythmic respiratory drive, and the actions of neuromodulators that control respiratory frequency, and functional development of the phrenic nerve and diaphragm musculature [28, 29]. During parturition, breathing movements are completely inhibited. Immediately after birth, respiratory activity which is intermittent in the fetus becomes continuous in the newly born infant. However, prematurity can alter the development and maturation of some of these mechanisms, and therefore most of the ELBW infants fail to establish sustainable and efficacious respiratory activity $[30,31]$. Experimental findings suggest that the inhibitory role played by the placenta depends on prostaglandins [32]. Of interest is the importance of the HeringBreuer inhibitory reflex, which is functional within the tidal breathing range and exerts a tight control on the breathing pattern of the term infant, is not altered by prematurity, and is thus vital in the first weeks of postnatal life [33]. However, excessive distensibility, distortion and compliance of the thoracic cage and weakness of the respiratory muscles may render respiratory efforts in the ELGAN inefficient [34].

After birth, alveolar hypoxia produces an immediate increase in ventilation followed by a later decrease. Conversely, high oxygen concentrations produce an immediate decrease in ventilation followed by hyperventilation [35]. In a recent study by Bookatz et al. [36], asphyxiated newborn rat pups were resuscitated with different oxygen concentrations. Time to onset of diaphragmatic activity was significantly shorter in the pups recovered in room air as compared to those ventilated with pure oxygen. Seemingly, a sustained increase in peripheral chemoreceptor drive during hypoxia will oppose central depression of respiration. Hence, hyperoxia during resuscitation could suppress peripheral chemoreceptor drive and delay re-initiation of breathing [37]. In a recent meta-analysis of studies performed in asphyxiated newborn infants, those resuscitated with room air established a spontaneous pattern of respiration significantly earlier than those resuscitated with pure oxygen [38].

There is a baseline concentration of $\mathrm{CO}_{2}$ that is essential for the stimulation of pacemaker cells of central respiratory chemoreceptors. The level of $\mathrm{CO}_{2}$ below which breathing ceases is known as the apnoeic threshold [39]. Interestingly, the apnoeic threshold of newborn infants is 
very close to the baseline $\mathrm{pCO}_{2}$ and therefore, hyperventilation caused by the use of high tidal volumes, high pressures or elevated respiratory rates would be sufficient to propel $\mathrm{pCO}_{2}$ below threshold [40]. However, although hypercapnia increases respiratory muscle activity, the effect of this stimulus on the balance between upper airway and chest wall muscle activation is different. Upper airway muscles, as opposed to chest wall muscles, exhibit a high $\mathrm{CO}_{2}$ threshold, thus explaining why some preterm infants develop obstructive apnoea [41].

\section{Respiratory Adaptation of the ELGAN Immediately} after Birth

Lung morphogenesis and repair are characterized by a complex sequence of cell-to-cell interactions of endodermal and mesodermal origins, which has evolved into an alveolar structure that can effectively exchange gases between the circulation and the alveolar space [42]. ELGANs are born at the end of the canalicular and beginning of the saccular stage of lung development. Their lungs therefore are formed by immature respiratory units called saccules. Saccules are characterized by lacking secondary septation, thus having a reduced gas exchange surface. In addition, alveolar type II cells are poorly represented and surfactant production is limited. It is important to note that septa between saccules are thick and contain two networks of capillaries rendering gas exchange difficult. Moreover, mesenchymal tissue contains low elastin and collagen, therefore having limited elastic properties [43-46]. Finally, the thoracic cage of ELGANs is extremely compliant, therefore having the tendency to collapse during forced inspiratory movements [34]. Taken together, these factors cause reduced lung compliance and limited thoracic expansion during inspiration, reduced elasticity and a lack of surfactant that may hinder the establishment of functional residual capacity (FRC). In addition, these factors also provoke a tendency towards airway and alveolar collapse (atelectasis) during expiration $[47,48]$. As a consequence, most ELGANs will need positive inspiratory pressure immediately after birth to achieve lung expansion, and positive end-expiratory pressure (PEEP) to adequately establish FRC. In fact, recent reports indicated that $60-70 \%$ of the infants born at 26-28 weeks' gestation, and every baby born at or less than 25 weeks was intubated in the DR almost immediately after birth and received endotracheal intermittent positive pressure ventilation with end-expiratory pressure or non-invasive continuous positive airway pressure (CPAP) $[49,50]$.
Inflammatory Response of the Immature Lung to Stretch Forces

Experimental as well as clinical research has provided substantial evidence to infer that overstretching of the immature lung immediately after birth causes lung inflammation, which may increase morbidity and mortality in the ELBW infants $[51,52]$. Of note is that most of the infants delivered before 30 weeks' gestation have been exposed to inflammatory or infectious processes in utero [51-56]. Further, resuscitation of ELBW infants still includes routine endotracheal intubation, positive-pressure ventilation, and high oxygen supplementation in many institutions $[8,11,16,18,19,25,26,57-59]$. Recent surfactant trials have promoted the use of intubation and administration of surfactant directly in the DR as a protective strategy to avoid respiratory insufficiency [60, 61]. Although the use of prenatal corticosteroids has become the standard practice for preventing respiratory distress syndrome in preterm infants, its anti-inflammatory effect against prenatal lung inflammation and postnatal pro-inflammatory interventions such as oxygen, lung stretching or infection is still to be deciphered. Therefore, evaluating the consequences of resuscitation manoeuvres as a second inflammatory hit to the lung has become a matter of interest in recent years.

Using tidal volumes that would be considered adequate for a normal lung to initiate ventilation of the immature lung filled with fluid may cause lung injury secondary to overstretching [20-23, 60-62]. Indeed, administration of supraphysiological tidal volumes to immature lambs, even for short periods of time, inhibited the positive effect on lung mechanics of subsequently administered surfactant. However, disruption of lung mechanics was not accompanied by alterations in oxygen exchange, and $\mathrm{paO}_{2}$ increased significantly in these animals [2024]. Similar results were found for human infants given late rescue treatment of surfactant. There was no correlation between early improvement in oxygenation and lung volume changes [60]. These findings may be related to changes in ventilation-perfusion matching within the lung. Furthermore, newborn lungs with adequate surfactant content can be ventilated at high pressures (consequently large tidal volumes) at least for short time periods (10 min) with no undesired side effect, as the alveoli expand synchronously and the inspired gas is distributed uniformly in the parenchyma [63]. However, ventilation with high tidal volumes for very immature lungs at the end stage of the canalicular and beginning of the saccular phase, in the absence of sufficient surfactant in the alveolar surface and elasticity in the interstitium, will lead to 
an uneven distribution of gas. Hence, some alveoli will alternatively overstretch (volutrauma) and collapse, while others will remain unexpanded (atelectotrauma). This result should be anticipated because the unventilated fetal lung with a high fluid content would not have time to recruit a sufficient number of alveoli that would approach the maximal lung volume $[62,64]$.

In addition to the physical injury to the immature lung, high-stretch ventilation using supranormal lung tidal volumes promotes the release of various inflammatory mediators into the alveolar space [65-68]. Among these inflammatory mediators, the pro-inflammatory cytokine tumour necrosis factor (TNF), which mediates CXC chemokine expression in models of lung inflammation, has received much attention, and its role remains controversial $[69,70]$. Despite the strong evidence that TNF is able to influence the progression of pulmonary oedema by altering the function of epithelial and endothelial cells, the predicted net effects of TNF on pulmonary oedema formation are conflicting in the literature. Thus, TNF may either promote pulmonary oedema by increasing epithelial and endothelial permeability [71, 72] or oppose oedema by enhancing fluid re-absorption [73], depending on the differential signalling of TNF receptors, specifically p55 and p75. Both soluble TNF receptors, which are expressed by many different cell types such as alveolar, endothelial or epithelial cells, can signal through different intracellular pathways and may induce different cellular responses. For example, activation of p55 receptor favours high-stretch oedema formation, while p75 receptor activation may play an opposing role [74]. These results demonstrate a novel role for TNF signalling, specifically through the $\mathrm{p} 55$ receptor, in promoting high-stretch-induced pulmonary oedema, which is apparently independent of its effects on neutrophil recruitment. If confirmed, these findings could imply a novel therapeutic approach for high-stretch lung damage in the coming future by modulating the TNF-signalling pathway.

\section{Clinical Interventions Meant to Reduce High-Stretch}

Damage to the Lung

Until a clear understanding of the intrinsic molecular mechanisms implicated in the development of inflammatory lung damage is achieved, some clinicians facing the necessity of ventilating ELBW infants have pursued the use of less aggressive and equally effective ventilation modalities.

CPAP was developed for infants with respiratory distress syndrome (RDS) by Gregory et al. [75] in 1971. How- ever, since the introduction of surfactant and more efficient devices especially designed for mechanical ventilation of the newborn, the use of CPAP as primary therapy for RDS in preterm infants declined. Interestingly, CPAP has been again used as a first-choice therapy for neonatal RDS in recent years [59, 76-83].

CPAP is a technique of respiratory support that generates a continuous distending pressure to the lung and is delivered to spontaneously breathing infants with RDS or apnoea. Typically, a pressure of $4-8 \mathrm{~cm} \mathrm{H}_{2} \mathrm{O}$ is used to distend airways and alveoli, thus impeding lung collapse during expiration. Numerous advantages have been described in the use of CPAP. These include the improvement of lung volume expansion and the achievement of FRC. In addition, CPAP improves ventilation-perfusion matching while decreasing atelectasis and pulmonary vascular resistance, resulting in an improvement in oxygenation. Seemingly, the use of CPAP enhances the release of surfactant and helps maintain surfactant present on the alveolar surface. Of note, CPAP stabilizes the chest wall and dilates the airways. In doing so, it reduces inspiratory resistance, increases lung compliance, counteracts paradoxical movements and reduces thoraco-abdominal asynchrony of the chest wall. Consequentially, a larger tidal volume is possible for a given applied pressure and a lower inspiratory fraction of oxygen needed to attain adequate oxygenation, and therefore, the work of breathing could be substantially reduced [76-78]. However, there are some problems associated with the use of CPAP. Apparently, the incidence of air leak in the thoracic cavity (pneumothorax, pneumomediastinum, pneumopericardium) is increased, and there is a risk of overdistension in infants with adequate lung compliance. In addition, the use of CPAP does not allow the administration of prophylactic surfactant in the DR [76].

The question is whether it is possible to use early CPAP treatment in the DR for ELBW infants or ELGAN in an attempt to reduce acute complications associated with intubation, as well as long-term respiratory consequences of various types of trauma to the lung caused by mechanical ventilation. At birth, the lungs are unaerated and filled with fluid. Following delivery, aeration must occur to establish FRC. Commonly, ELGANs are not able to achieve FRC themselves. Either CPAP during spontaneous breathing or PEEP during ventilation helps establish FRC and improve oxygenation [77]. Finer et al. [49] randomized 104 ELBW infants of $<28$ weeks' gestation to CPAP/PEEP $(n=55)$ or no CPAP/PEEP $(n=49)$ in the DR during resuscitation immediately after delivery, avoiding routine intubation for surfactant administration. Al- 
though most infants $<24$ weeks' gestation required intubation, Finer et al. demonstrated that over $50 \%$ of the infants in the experimental group were successfully randomized to CPAP in the DR. Other studies have confirmed the feasibility of using early CPAP in the DR in ELBW infants [26, 57-59]. Interestingly, in a recent randomized trial, combining early nasopharyngeal CPAP with sustained inflation to non-aggressively recruit the lung in ELBW infants immediately after birth was compared with the conventional approach of intubation [59]. The number of intubations at $72 \mathrm{~h}$ after birth and the number of doses of surfactant given were substantially reduced with less BPD developed in those ELBW infants treated with early CPAP compared to those with the conventional approach. To date, the CPAP or Intubation at Birth (COIN) Trial is the most extensive randomized, multicentre trial launched to compare the use of CPAP with early intubation in the DR [50]. In this study, 610 preterm infants born at 25 weeks' 0 days' to 28 weeks' 5 days' gestation who were able to breathe spontaneously at 5 min of age but still needed assistance, were assigned to either CPAP alone or intubation and ventilation [50]. CPAP was set at $8 \mathrm{~cm} \mathrm{H}_{2} \mathrm{O}$, which is in the highest usual range in the DR. Of note is that there were no protocol requirements for the administration of surfactant for infants in either arm, and no specific extubation criteria. The rate of death or BPD at 36 weeks' gestation did not differ between both groups, although patients in the CPAP group needed less oxygen at 28 days after birth and had fewer days of ventilation. The CPAP group was associated with a greater incidence of pneumothorax, compared to those in the intubation group (9.1 vs. 3.0\%, respectively; $\mathrm{p} \leq 0.01$ ). As recently stated by Finer [84], although this study does not provide evidence of the superiority of CPAP over early surfactant, further studies will be needed to assess the best strategy for ventilation of ELGANs in the DR.

\section{Oxygenation in the DR}

\section{Oxygen in the Fetal-to-Neonatal Transition}

Fetuses have a partial pressure of oxygen of $15-25 \mathrm{~mm}$ $\mathrm{Hg}$ in the arterial blood [85], corresponding to an arterial oxygen saturation of approximately $50 \%[86,87]$. Several factors are important in the determination of oxygen content of the blood including oxygen saturation or binding with the haemoglobin. Importantly, these factors vary with gestational age of the fetus $[88,89]$.
Haemoglobin Concentration, Specifically the Concentration of Fetal Haemoglobin

Haemoglobin is the oxygen-carrying molecule in the blood, thus its concentration will affect the oxygen content of blood. Particularly, the haemoglobin concentration will increase when fetal hypoxia is present over a prolonged period. Conversely, in pathological conditions with fetal anaemia, such as fetal blood loss or haemolysis, the oxygen content of blood is greatly reduced. Further fetal haemoglobin $(\mathrm{HbF})$, which has an increased oxygen-binding capacity with a left-shifted oxygen dissociation curve, constitutes the majority of haemoglobin and has physiological relevance for fetal growth and development under a low-oxygen (relatively hypoxic) environment. Indeed, ELBW infants have more than $90 \%$ of their red blood cells containing $\mathrm{HbF}$ [90].

Oxygen-Binding Capacity/Oxygen Dissociation

Curve

Fetuses are growing and developing in a relatively hypoxic environment. To overcome such a disadvantageous condition, they produce $\mathrm{HbF}$ that can pick up the oxygen molecule from the maternal venous side (approximately $70 \%$ saturation) and deliver it to the target organs/tissues. $\mathrm{HbF}$ is composed of two $\alpha$-chains and two $\gamma$-chains. The left-shifting of the oxygen dissociation curve of $\mathrm{HbF}$ indicates the increased binding between $\mathrm{HbF}$ and oxygen. This may be related to the decreased binding of 2, 3-diphosphoglycerate by $\mathrm{HbF}$ ( $\gamma$-chains). Orzalesi and Hay [91] demonstrated that in whole blood, the in vivo effect of 2,3-diphosphoglycerate on the oxygen affinity of $\mathrm{HbF}$ was approximately $40 \%$ of that of adult $\mathrm{Hb}$. Interestingly, the oxygen affinity of fetal blood decreases during gestation and depends on the relative proportions of adult $\mathrm{Hb}$ and $\mathrm{HbF}$ and on the level of red cell 2,3-diphosphoglycerate. However, Bard and Teasdale [90] showed that gestational age had no effect on 2,3-diphosphoglycerate levels and $\Delta \mathrm{pH}$ between plasma and red cell. They therefore concluded that the decrease in fetal oxygen affinity as gestation progresses is related mainly to the increase in the amount of adult $\mathrm{Hb}$, and the levels of 2,3-diphosphoglycerate or $\Delta \mathrm{pH}$ between plasma and red cells are not a function of gestational age.

The Bohr Effect of $\mathrm{HbF}$

The Bohr effect describes the reciprocal relationship between oxygen and acid reactive radicals in their interaction with haemoglobin. Kirschbaum [88] examined the Bohr effect over a range of saturation (10-87\%) in human fetal blood samples and suggested that the difference in 
the oxygen affinity to adult $\mathrm{Hb}$ and $\mathrm{HbF}$ was not attributable to differences between haemoglobin subtypes but to differences in the internal composition of erythrocytes. Thus, components that affect the proton content of erythrocytes, including $\mathrm{CO}_{2}$, may influence oxygen-haemoglobin interaction.

After birth, the oxygen partial pressure rises to $50-80$ $\mathrm{mm} \mathrm{Hg}$ [87]. House et al. [92] showed that the mean arterial oxygen saturation was $59,68,82$ and $90 \%$ at $1,2,5$ and 15 min of life, respectively. For obvious reasons, depending on the concentration of oxygen being administered to the neonates, the degree and rate of the increase in oxygen saturation as well as the partial pressure of oxygen vary. The physiological importance of the degree and rate of increase in oxygen saturation during the transition from a low- to a high-oxygen environment is undetermined. Nonetheless, it is reasonable to 'smoothen' the transition in addition to the avoidance of excessive oxidative stress to the ELBW infants in this perinatal transition period.

\section{Monitoring Oxygen Saturation in the First Minutes of Life}

Rabi et al. [93], Kamlin et al. [94], and Mariani et al. [95] described the gradual increase in oxygen saturation measured by pulse oximetry in healthy neonates. Interestingly, in the study of Rabi et al. [93], infants delivered by caesarean section had 3\% lower oxygen saturations and also took longer time to reach a stable oxygen saturation of $\geq 85 \%$ when compared to infants delivered by vaginal delivery. Kamlin et al. [94] studied both term and preterm healthy infants $(n=175)$ who did not require resuscitation or supplementary oxygen. They reported that the median saturation at 5 min of life was 90 and $87 \%$ in term and preterm neonates, respectively. Furthermore, there was a significant gradient between the preductal and postductal oxygen saturations during the first 15 min of life, which was confirmed by the studies of Mariani et al. [95]. With regard to these changes in oxygen saturation after birth, Saugstad [96] commented that before initiating oxygen supplementation, care givers in the $\mathrm{DR}$ should be aware that median $\mathrm{SpO}_{2}$ does not reach preductal levels of $90 \%$ until 5 min after cord clamping in vaginal deliveries. Moreover, in infants born by caesarean section and preterm infants, it may be delayed up to 2-3 min or even more in those infants in the lower range of normality to reach an $\mathrm{SpO}_{2}$ of $90 \%$ or more [96].

\section{Lowering Oxygen Concentrations}

The transition from the fetal to neonatal life is associated with an increase in oxygenation and the inevitable oxidative stress [96-100]. While the associated oxidative stress is a double-edged sword, the anti-oxidative capacity of the system plays an important role to facilitate the transition as well as to combat the potential oxidative stress induced injury. Indeed, the pro-oxidant state after birth may contribute to many metabolic and cellular functions of the neonate $[101,102]$. Conversely, the compromised anti-oxidative capacity of the system may predispose to the occurrence of oxidative-stress-induced injury $[103,104]$. Of note, the anti-oxidative system of the fetus matures late in gestation, and is especially compromised in ELBW infants [104]. Interestingly, these ELBW infants are at an increased risk of developing oxygen radical diseases of neonatology, including ROP, BPD, necrotizing enterocolitis (NEC) and IVH [105-107].

In order to avoid oxidative stress caused by excessive oxygen administration to the ELBW infant, several feasibility trials have been performed to prove whether resuscitation was possible using initial lower oxygen concentrations and titrating $\mathrm{FiO}_{2}$ according to targeted values of $\mathrm{SpO}_{2}$. Wang et al. [108] recently reported that the resuscitation of preterm neonates (24-31 weeks' gestation) with room air achieved a significantly lower oxygen saturation at $3 \mathrm{~min}$ of life than that when $100 \%$ oxygen was used ( 55 vs. $87 \%$, respectively; $\mathrm{p}<0.05$ ) with no differences in neonatal mortality and morbidity. However, in a high percentage of cases $\mathrm{FiO}_{2}$ had to be switched to $100 \%$ because infants did not meet targeted $\mathrm{SpO}_{2}$. Escrig et al. [109] compared the effect of 30\% oxygen used as initial $\mathrm{FiO}_{2}$ in the resuscitation of ELBW infants (24-28 weeks' gestation) on the oxygen saturation with that when $90 \%$ oxygen was used. There was no difference in the minuteto-minute saturation where a stable oxygen saturation of $85 \%$ was reached by $5-7 \mathrm{~min}$ in both groups. Rabi et al. [110], in a study to compare the temporal changes in oxygen saturation in 106 preterm infants (mean gestational age of 29 weeks) using different oxygen administration strategies to target the oxygen saturation of $85-92 \%$ measured by pulse oximetry placed at the right wrist, confirmed the effectiveness of using a high starting oxygen concentration (100\%).

The Neonatal Resuscitation Program and the International Liaison Committee on Resuscitation recently recommend the monitoring of oxygen saturation when preterm neonates need resuscitation and/or oxygen [111, 112]. The placement of pulse oximetry in ELBW infants is indeed feasible and provides useful information regarding the oxygenation of blood to guide the therapy, in addition to the understanding of the transition from fetal to neonatal life. While most studies were performed in 
ELBW infants requiring resuscitation, it is essential to obtain normative data of the temporal profile of the oxygenation in blood. The trajectory of increasing oxygen saturation after birth in the non-resuscitated newborn infant would be the best available model to mimic during resuscitation.

When $100 \%$ or high oxygen concentration is being used to resuscitate ELBW infants, we believe that there may be an increased risk of injuries related to hyperoxiainduced oxidative stress. Indeed, Deulofeut et al. [113] reported that by avoiding hyperoxia, the short- and longterm outcomes of ELBW infants could be improved. Furthermore, in studies of term and near-term neonates, using $100 \%$ oxygen in the resuscitation has been associated with increased cardiac and renotubular damages [103] in addition to the increased oxidative stress shown in whole-blood markers (oxidized glutathione content) that persisted up to 28 days after birth [114]. In animal models of asphyxia, the increased oxidative stress has been related to impaired organ function and/or injury as in the heart, lung, brain, intestine, kidney, adrenal glands, and platelets [115-121]. Further, an epidemiological link between resuscitation with supplemental oxygen and childhood leukaemia has been suggested by Naumburg et al. [122] and Spector et al. [123]. Nonetheless, there is a lack of data on the effects of room air and oxygen in the resuscitation of preterm neonates.

However, some reports suggest that $100 \%$ re-oxygenation may be a beneficial therapy that was generally thought to be non-toxic and to have faster oxygen debt replenishment [124, 125], despite the greater oxidative stress. In the resuscitation of asphyxiated neonates, there is a delicate balance between oxidative-stress-related injury with the re-oxygenation/reperfusion process and persistent hypoxia/ischaemia damage. Resuscitation protocols using different oxygen concentrations may affect the balance between these two processes. While hyperoxic resuscitation exaggerates oxidative-stress-related injury and normoxic resuscitation may allow the continuation of anaerobic metabolism, both may result in more cellular damage/death. The oxidative-stress-related injury may be particularly important in ELBW infants who have a compromised anti-oxidant reserve system [99, 104]. The Neonatal Resuscitation Program and the International Liaison Committee on Resuscitation have indicated that there is insufficient evidence to specifically recommend an initial oxygen concentration for resuscitation of ELGANs; however, both adverted to the possible toxic effects of oxygen, especially in preterm infants, and recommended strict control of physical constants and oxygenation $[111,112]$. In recent years, the use of pulse oximetry as the guidance for the administration of supplemental oxygen has taken over the clinical evaluation of colour and has been encouraged [96].

\section{Temperature Control in the DR}

\section{Tendency of the ELBW Infant to Hypothermia}

ELBW infants experience limited capacity to control body temperature after birth. Moreover, low body temperature has been associated as an independent risk factor for mortality of preterm infants upon the admittance to the NICU [126].

In 1997, the World Health Organization provided the following definitions of normothermia and hypothermia for newborn infants [127]:

- Normal range: $36.5-37.5^{\circ} \mathrm{C}$;

- Potential cold stress: $36.0-36.5^{\circ} \mathrm{C}$; cause for concern;

- Moderate hypothermia: $32.0-36.0^{\circ} \mathrm{C}$; danger, immediate warming of the infant, and

- Severe hypothermia: $<32.0^{\circ} \mathrm{C}$; outlook grave, skilled care urgently needed.

The newborn infant exhibits an immature thermoregulation when compared to the older child or the adult. The difficulty in maintaining an adequate and stable core temperature is directly related to its gestational age and/ or weight. Exhaustive studies performed by the group of researchers of Uppsala have described the peculiar physiological characteristics of the newborn infant which favour their thermal instability even under radiant heaters or incubators. Such characteristics include: (1) inability to shiver; (2) increased surface area to body weight ratio; and (3) extremely thin insulator subcutaneous tissue [128-133]. Of note, the heat loss by convection, evaporation and radiation usually far exceeds the heat production after birth. Thus, if measures are not promptly initiated to counteract this negative balance, body temperature will fall, independently of the environment temperature, during the first $12 \mathrm{~h}$ of life [128]. In addition, preterm infants are more prone than term infants to develop hypothermia, which is in part related to the thin subcutaneous fat for insulation to reduce heat loss. Moreover, preterm infants have less brown fat to produce heat and less glycogen store than term infants. The immature stratum corneum is relatively deficient in keratin content, resulting in an inadequate barrier to prevent large transepidermal heat and water losses soon after delivery. Further, preterm infants have an inefficient vascular control for thermoregulation [126]. 
Cold stress may negatively influence the physiology of fetal-to-neonatal transition. It has been shown that hypothermia can delay the initiation of spontaneous breathing and lead to respiratory distress and hypoxia [134, 135]. Hypothermia may also alter the circulatory changes which characterize adaptation from intra-uterine to extra-uterine environment, resulting in persistent pulmonary hypertension [136, 137]. Moreover, hypothermia causes negative metabolic effects such as hypoglycaemia [138-140] and metabolic acidosis [137], and impairs coagulation [141]. In infants with severe hypothermia, cold stress may lead to renal insufficiency, NEC and even death [138]. Recently, it has been shown that there is a relationship between reduced admission body temperature and both late-onset sepsis and in-hospital mortality [142].

In a study of the transepidermal water loss and heat exchange with the environment in relation with gestational age, Hammarlund et al. [129-131] found that preterm infants less than 30 weeks' gestation cared for in a humidity around $20 \%$ (that is present under the average radiant heater) continued to lose $20-75 \mathrm{~g} / \mathrm{m}^{2} / \mathrm{h}$ of water by evaporation from the skin during the first day of life. This evaporative cooling effect equates to a heat loss of $13.3-50 \mathrm{~W} / \mathrm{m}^{2} / \mathrm{h}$. Thus, naked infants born before 28 weeks' gestation need $40^{\circ} \mathrm{C}$ in order to maintain a normal temperature in $20 \%$ ambient humidity, while increasing humidity to $60 \%$ can halve the evaporative losses.

\section{Achievement of a Neutral Thermal Environment}

A neutral thermal environment (NTE) is one in which standard metabolic rate or oxygen consumption is minimal. In an NTE, temperature regulation is exclusively achieved by non-evaporative physical processes [143]. Silverman et al. [144] were the first to show in a controlled study that thermal environment was important for the survival of preterm infants. They demonstrated that maintaining body temperature through the control of thermal environment during the first 5 days of life (Isolette temperature of $29 \mathrm{vs} .32^{\circ} \mathrm{C}$, with relative humidity in both groups sets between $80-90 \%$ and resultant mean of the average axillary temperature $2.6^{\circ} \mathrm{C}$ higher in normothermic group) reduced mortality in low-birth-weight infants. Other clinical trials of preterm infants yielded similar observations [145].

Heat loss begins immediately after birth; therefore, caregivers in the DR should promptly intervene to reduce the risk of hypothermia. Hence, immediately after birth infants should be placed under radiant warmer and be wrapped and dried with warm cloths, especially the head.
These measures, which usually suffice in a term newborn, are insufficient for preterm infants, who inevitably lose heat in the DR and become hypothermic rapidly. Thus, admission temperature was $<35^{\circ} \mathrm{C}$ in $40 \%$ of all infants born before 26 weeks' gestation within the United Kingdom and the Republic of Ireland during 1995 [1], and in $47 \%$ of preterm infants $<1,500$ g included in the $2002-$ 2003 cohort of the Neonatal Research Network had less than $36^{\circ} \mathrm{C}$ at admission [8]. Different studies demonstrated that a convectively heated incubator was more efficient than an open radiant warmer in maintaining an NTE $[146,147]$, but placing a preterm newborn in an Isolette after delivery would make resuscitation manoeuvres difficult. Therefore, research was oriented towards the prevention of heat loss using wrappers of different materials. The first study in this area, reported by Baumgart et al. [148], compared the heat loss in classical warmer beds with plastic-walled chambers and that in thin, flexible and transparent plastic blankets aiming to diminish the infant's exposure to convective air currents. Interestingly, there was an important reduction in insensible water loss as well as a decreased radiant power demand in the group randomized to plastic blankets, suggesting that convection is an important factor influencing evaporation in neonates and this may be diminished by plastic wraps. Moreover, plastic blankets have shown to reduce metabolic derived heat loss; infants wrapped with plastic blankets had a substantial reduction in oxygen consumption and in heart rate $[148,149]$. Seemingly efficacious, a series of different heat shields have been tested with variable success, such as plastic body hoods [150] or barriers made with another kind of material, like a semipermeable polyurethane membrane that allows free exchange of water and air [151]. Moreover, LeBlanc [152] showed that occlusive wraps made of polyethylene could transmit the long wavelength energy corresponding to radiant heat. Thereafter, several studies have demonstrated that polyethylene occlusive skin wrapping of the wet body applied immediately after birth diminished postnatal fall in temperature of very immature infants by reducing evaporative and convective heat loss $[153,154]$. Theoretically, there is a risk of overheating ELBW infants when the polyethylene/polyurethane wraps are used. This may be of great concern to avoid hyperthermia $\left(>38^{\circ} \mathrm{C}\right)$, especially in infants at risk of hypoxic-ischemic encephalopathy. Nonetheless, hyperthermia is an infrequent complication that may be reduced by the use of servocontrol thermoregulation during resuscitation [155].

In a recent Cochrane review, 6 interventions with 295 preterm infants randomized to different methods to pre- 
vent hypothermia at birth were analysed [156]. It was concluded that plastic barriers were effective in newborns $<28$ weeks' gestation in the prevention of evaporative loss. In addition, thermal mattresses showed an equivalent effect in infants $<1,500 \mathrm{~g}$ as that of plastic barriers. Additional measures, including the use of caps that had previously demonstrated to reduce heat exchange between head and ambient air, showed borderline effectiveness in reducing heat loss in the Cochrane review [156].

\section{Delayed versus Early Cord Clamping}

The optimal timing of cord clamping has not yet been established. However, delayed cord clamping may at least offer several theoretical advantages over early clamping of the cord, which has been postulated to put newly born infants at risk of hypovolaemic damage and iron loss, as well as of several blood disorders and type 2 diabetes, as a consequence of loss of haematopoietic stem cells or anaemia within the 6 first months of life [157-159]. On the contrary, delayed cord clamping may have possible complications resulting from overloading the neonatal blood volume, thus increasing the possibility of developing polycythaemia, respiratory distress or jaundice [160].

In a recent systematic review, researchers compared the effects of early (within $10 \mathrm{~s}$ after birth) versus delayed (after 3 or more minutes after birth or after the cord stopped pulsing) in 1,912 term neonates [161]. Delayed cord clamping was associated with an $80 \%$ reduction in the newborn's likelihood of being anaemic at $24-48 \mathrm{~h}$ and halved the risk of being anaemic at 2-3 months. However, the statistically significant differences between the two groups disappeared at 6 months. Moreover, haematological status as measured by haemoglobin, haematocrit or serum ferritin levels was improved in both short and long term. Interestingly, the risk of developing jaundice, respiratory distress, or admittance to the NICU was not increased [161]. Interestingly, although polycythaemia was more frequent in the delayed group, no physical signs were evident, and thus these infants did not require exchange transfusion [161]. Hutton and Hassan [161] concluded that delaying clamping of the umbilical cord in term neonates for a minimum of $2 \mathrm{~min}$ following birth is beneficial to the newborn, extending into infancy.

In the preterm infant, especially in the ELGAN, delaying cord clamping has some additional difficulties because the infant is immediately handed to the clinician to initiate resuscitation. However, in a recent systematic meta-analysis of randomized trials including 454 infants below 37 weeks' gestation with delayed (30 s or more) or immediate (less than $20 \mathrm{~s}$ ) cord clamping, it was concluded that delaying clamping for $30 \mathrm{~s}$ was a safe procedure, and offered major benefits with the reduction in blood transfusions and the incidence of IVH [162].

\section{Conclusions}

It is becoming more and more evident that medical interventions aiding ELBW infants to achieving a successful transition into the extra-uterine world is not exempt from short- and long-lasting complications. The use of excessive pressure or volume (overstretching) and oxidative aggression (reactive oxygen and nitrogen species) may cause acute damage to the lung and other organs. Moreover, it may induce structural modifications that will reduce functional capacity and promote chronic illness in the adult life. ELGANs are at a high risk of hypothermia and its deleterious consequences in the DR and during transport to the NICU; avoidance of cold stress should be emphasized. Delayed cord clamping for at least $30 \mathrm{~s}$ is a safe procedure and has apparently no negative effects.

We conclude that available technology may, in the near future, enable individualization of ventilatory and oxygenation needs, thus minimizing physical and oxygen-derived damage. In addition, cold stress can be avoided with a strict control of the infant's temperature. Achievement of these goals requires implementation of the concept of 'delivery room intensive care unit' (DRICU). The DRICU would provide the high-risk neonate with updated technology, as well as with highly qualified personnel, that can perform the optimal resuscitation at all times, thus improving the chance of a morbidity-free survival.

\section{Acknowledgements}

Financial aid was obtained from the Research Foundation Hospital La Fe to M.A., and Research Grant PI05/1505 from the Fondo de Investigaciones Sanitarias (Instituto Carlos III; Ministry of Health) to M.V. 


\section{References}

1 Costeloe K, Hennessy E, Gibson A: The EPIcure study: outcomes to discharge from hospital for infants born at the threshold of viability. Pediatrics 2000;106:659-671.

-2 Horbar JD, Badger GJ, Carpenter JH: Trends in mortality and morbidity for very low birth weight infants 1991-1999. Pediatrics 2002; 110:143-151.

3 Effer SB, Moutquin JM, Farine D, Saigal S, Nimrod C, Kelly E, et al: Neonatal survival rates in 860 singleton live births at 24 and 25 weeks gestational age. A Canadian multicentre study. Br J Obstet Gynecol 2002;7:740745.

4 Rijken M, Gerlinde M, Stoclhorst S: Mortality and neurologic, mental and psychomotor development at 2 years in infants born less than 27 weeks' gestation: the Leiden followup project on prematurity. Pediatrics 2003; 112:351-358.

5 Vanhaesebrouck P, Allegaert K, Bottu J, Debauche C, Devlieger H, Docx M, et al: The EPIBEL study: outcomes to discharge from hospital for extremely preterm infants in Belgium. Pediatrics 2004;114:663-675.

6 Markestad T, Kaaresen P, Ronnestad A: Early death, morbidity and need of treatment among extremely premature infants. Pediatrics 2005; 115:1289-1298.

$\checkmark 7$ Tommiska V, Heinonen K, Lehtonen L, Renlund M, Saarcla T, Tammcla O, Virtanen M, Fellman V: No improvement in outcome of nationwide extremely low birth weight infant population between 1996-97 and 19992000. Pediatrics 2007;119:29-36.

$\checkmark 8$ Fanaroff AA, Stoll BJ, Wright LL, Carlo W, Ehrenkrantz RA, Stark AR, Bauer CR, Donovan EF, Korones SB, Laptook RA, Lemmons JA, Oh W, Papile LA, Shankaran S, Stevensons DK, Tyson JE, Poole WK; NICHD Neonatal Research Network: Trends in neonatal morbidity and mortality for very low birth weight infants. Am J Obstet Gynecol 2007; 196: 147.e1-147.e8.

9 Field DJ, Dorling JS, Manktelow BN, Draper ES: Survival of extremely premature babies in a geographically defined population: prospective cohort study of 1994-9 compared with 2000-5. BMJ 2008 online; doi: 10.1136/ bmj.39555.670718.BE (downloaded 2 July 2008).

10 Landmann E, Misselwitz B, Steiss JO, Gortner L: Mortality and morbidity of neonates born at <26 weeks gestation (1998-2003). A population based study. J Perinatol 2008 online; doi: 10.1515/JPM.2008.016 (downloaded 25 June 2008).
11 Branco de Almeida MF, Guinsburg R, Martinez FE, Procianoy RS, Rodrigues Leone C Martins Marba ST, Sousa Suppo Rugolo LM, Hecker Luz J, de Andrade Lopes JM: Perinatal factors associated with early deaths of preterm infants born in Brazilian network on neonatal research centers. J Pediatr (Rio J) 2008;84: online edition; doi: 10.2223/ JPED.1787 (downloaded 2 July 2008).

12 Cifuentes J, Bronstein J, Phibbs CS, Phibbs RH, Schmitt SK, Carlo WA: Mortality in low birth weight infants according to level of neonatal care at hospital of birth. Pediatrics 2002;109:745-751.

13 Johansson S, Montgomery SM, Ekbom A, et al: Preterm delivery, level of care, and infant death in Sweden: a population based study. Pediatrics 2004;113:1230-1235.

14 Goodman DC, Fisher ES, Little GA, Stukel TA, Chang CH, Schoendorf KS: The relation between the availability of neonatal intensive care and neonatal mortality. N Engl J Med 2002;346:1538-1544.

15 Phibbs CS, Baker LC, Caughey AB, Danielsen B, Schmitt SK, Phibbs RH: Level and volume of neonatal intensive care and mortality in very low birth weight infants. $\mathrm{N}$ Engl J Med 2007;356:2165-2175.

16 Hakansson S, Farooqi A, Holmgren P, Serenius F, Hogberg U: Proactive management promotes outcome in extremely preterm infants: a population-based comparison of two perinatal management strategies. Pediatrics 2004;114:58-64

17 Rieger-Fackeldey E, Schulze A, Pohlandt F, Schwarze R, Dinger J, Lindner W: Shortterm outcome in infants with a birth weight less than 501 grams. Acta Paediatr 2005;2: 211-216.

18 Kobaly K, Schluchter M, Minich N, Friedman H, Taylor GH, Wilson-Costello D, Hack M: Outcomes of extremely low birth weight $(<1000 \mathrm{~g})$ and extremely low gestational age ( $<28$ weeks) infants with bronchopulmonary dysplasia: effects of practice changes in 2000 to 2003. Pediatrics 2008;121:73-81.

19 Halvorsen T, Skadberg BT, Eide GE, Røksund OD, Markestad T: Better care of immature infants; has it influenced long-term pulmonary outcome? Acta Paediatr 2006;95 547-554.

20 Björklund LJ, Ingimarsson J, Curstedt T: Manual ventilation with a few large breaths at birth compromises the therapeutic effect of subsequent surfactant replacement in immature lambs. Pediatr Res 1997;42:348-355.

-21 Wada K, Jobe AH, Ikegami M: Tidal volume effects on surfactant treatment responses with the initiation of ventilation in preterm lambs. J Appl Physiol 1997;83:1054-1061.

-22 Ikegami M, Kallapur S, Michna J, Jobe AH Lung injury and surfactant metabolism after hyperventilation of premature lambs. Pediatr Res 2000;47:398-404.
23 Björklund LJ, Ingimarsson J, Curstedt $\mathrm{T}$, Larsson A, Robertson D, Werner O: Lung recruitment at birth does not improve lung function in immature lambs receiving surfactant. Acta Anaesthesiol Scand 2001;45: 986-993

24 Ingimarsson J, Bjorklund LJ, Curstedt T: Incomplete protection by prophylactic surfactant against the adverse effects of large lung inflations at birth in immature lambs. Intensive Care Med 2004;30:1446-1453.

25 Jobe AH: Transition/adaptation in the delivery room and less RDS: "Don't just do something, stand there!" J Pediatr 2005; 147:284286

26 Aly H, Massaro AN, Patel K, El-Mohandes AA: Is it safer to intubate premature infants in the delivery room? Pediatrics 2005;115: 1660-1665.

27 Greer JJ, Funk GD, Ballanyi K: Preparing for the first breath: prenatal maturation of respiratory neural control. J Physiol 2006;570: 437-444.

28 Blanco CE: Maturation of fetal breathing activity. Biol Neonate 1994;65:182-188.

29 Ballanyi K: Neuromodulation of the perinatal respiratory network. Curr Neuropharmacol 2004;2:221-243.

30 Rigatto $\mathrm{H}$ : Control of breathing in fetal life and onset and control of breathing in the neonate; in Polin RA, Fox WW, Abman SH (eds): Fetal and Neonatal Physiology, ed 3. Philadelphia, Saunders-Elsevier, 2004, pp 890-900.

31 Arsenault J, Moreau-Bussière F, Reix P, Niyonsenga T, Praud JP: Postnatal maturation of vagal respiratory reflexes in preterm and full-term lambs. J Appl Physiol 2003;94: 1978-1986.

32 Alvaro RE, Hasan SU, Chemtob S, Qurashi M, Al-Saif S, Rigatto H: Prostaglandins are responsible for the inhibition of breathing observed with a placental extract in fetal sheep. Respir Physiol Neurobiol 2004;144: 35-44.

>33 Thach B: Fast breaths, slow breaths, small breaths, big breaths: importance of vagal innervation in the newborn lung. J Appl Physiol 2001;91:2298-2300.

34 Mortola JP, Saetta M, Fox G, Smith B, Weeks S: Mechanical aspects of chest wall distortion. J Appl Physiol 1985;59:295-304.

35 Rehan V, Haider AZ, Alvaro RE, Nowaczyk B, Cates DB, Kwiatkowski K, Rigatto H: The biphasic ventilatory response to hypoxia in preterm infants is not due to a decrease in metabolism. Pediatr Pulmonol 1996;22:287294.

36 Bookatz GB, Mayer CA, Wilson CG, Vento M, Gelfand SL, Haxhiu MA, Martin RJ: Effect of supplemental oxygen on reinitiation of breathing after neonatal resuscitation in rat pups. Pediatr Res 2007;61:698-702. 
37 Bouferrache B, Filtchev S, Leke A, MarbaixLi Q, Freville M, Gaultier C: The hyperoxic test in infants revisited. Am J Respir Crit Care Med 2000;161:160-165.

- 38 Rabi Y, Rabi D, Yee W: Room air resuscitation of the depressed newborn: a systematic review and meta-analysis. Resuscitation 2007;72:353-363.

- 39 Rigatto H, Rehan V, Lemke RP, Idiong N, Hussain A, Cates D: Respiratory pacemaker cells responsive to $\mathrm{CO}_{2}$ in the upper medulla: dose response and effects of mediators. Pediatr Pulmonol 2000;30:359-367.

-40 Khan A, Qurashi M, Kwiatkowski K, Cates $\mathrm{D}$, Rigatto $\mathrm{H}$ : Measurement of the $\mathrm{CO}_{2}$ apneic threshold in newborn infants: possible relevance for periodic breathing and apnea. J Appl Physiol 2005;98:1171-1176.

-41 Carlo WA, Martin RJ, Difiore JM: Differences in $\mathrm{CO}_{2}$ threshold of respiratory muscles in preterm infants. J Appl Physiol 1988;65: 2434-2439.

-42 Torday JS, Rehan VK: Developmental cell/ molecular biologic approach to the etiology and treatment of bronchopulmonary dysplasia. Pediatr Res 2007;62:2-7.

43 Thebaud B: Angiogenesis and lung development. Neonatology 2007;91:291-297.

44 Stenmark KR, Abman SH: Lung vascular development: implications for the pathogenesis of bronchopulmonary dysplasia. Annu Rev Physiol 2005;67:623-661.

-45 Bland RD: Neonatal chronic lung disease in the post-surfactant era. Lessons learned from the authentic animal models. Biol Neonate 2005;88:181-191.

46 Rey-Parra GJ, Archer SL, Bland RD, Albertine $\mathrm{KH}$, Carlton DP, Cho SC, Kirby B, Haromy A, Eaton F, Wu X, Thebaud B: Blunted hypoxic pulmonary vasoconstriction in experimental neonatal chronic lung disease. Am J Respir Crit Care Med 2008, May 29. Epub ahead of print.

-47 Gerhardt T, Bancalari E: Chest wall compliance in full-term and premature infants. Acta Paediatr Scand 1980;69:359-364.

48 Heldt GP, McIlroy MB: Dynamics of chest wall in preterm infants. J Appl Physiol 1987; 62:170-174

-49 Finer NN, Carlo WA, Duara S, Fanaroff AA, Donovan EF, Wright LL, Kandefer S, Poole WK for the National Institute of Child Health and Human Development Neonatal Research Network. Delivery room continuous positive airway pressure/positive endexpiratory pressure in extremely low birth weight infants: a feasibility trial. Pediatrics 2004;114:651-657.

-50 Morley CJ, Davis PG, Doyle LW, Brion LP, Hascoet JM, Carlin JB: Nasal CPAP or intubation at birth of very preterm infants. $\mathrm{N}$ Engl J Med 2008;358:700-708.

-51 Jobe AH, Ikegami M: Mechanisms initiating lung injury in the preterm. Early Hum Dev 1998;53:81-94.
52 Kallapur SG, Jobe AH: Contribution of inflammation to lung injury and development. Arch Dis Child Fetal Neonatal Ed 2006;91: F132-F135.

53 Steel JH, Malatos S, Kennea N: Bacteria and inflammatory cells in fetal membranes do not always cause preterm labor. Pediatr Res 2005;57:404-411.

54 Goldenberg RL, Culhan JF, Iams JD, Romero $\mathrm{R}$ : Epidemiology and causes of preterm birth. Lancet 2008;371:75-84.

55 Thomas W, Seidenspinner S, KawczynskaLeda N, Kramer BW, Chmielnicka-Kopaczyk M, Marx A, Szymankiewicz M, Speer CP: Systemic fetal inflammation and reduced concentrations of macrophage migration inhibitory factor in tracheobronchial aspirate fluid of extremely premature infants. Am J Obstet Gynecol 2008; 198:64.e164.e6.

56 Goldenberg RL, Andrews WW, Goepfert AR, Faye-Petersen O, Cliver SP, Carlo WA, Hauth JC: The Alabama Preterm Birth Study: umbilical cord blood Ureplasma urealyticum and Mycoplasma hominis cultures in very preterm newborn infants. Am J Obstet Gynecol 2008;198:43.e1-43.e5.

57 Lindner W, Vossbeck S, Hummler H, Pohlandt F: Delivery room management of extremely low birth weight infants: spontaneous breathing or intubation? Pediatrics 1999; 103:961-967.

58 Ammari A, Suri MS, Milisavljevic V, Sahni R, Bateman DA, Sanocka U, Ruzal Shapiro C, Wung JT, Polin RA: Variables associated with the early failure of nasal CPAP in very low birth weight infants. J Pediatr 2005;147: 341-347.

59 Te Pas AB, Walther FJ: A randomized controlled trial of delivery room respiratory management in very preterm infants. Pediatrics 2007;120:322-329.

60 Kendig JW, Notter RH, Cox C, Reubens LJ, Davis JM, Maniscalco WM, Sinkin RA, Bartoletti A, Dweck HS, Horgan MJ, Risemberg $\mathrm{H}$, Phelps DL, Shapiro DL: A comparison of surfactant as immediate prophylaxis and as a rescue therapy in newborns of less than 30 weeks' gestation. N Engl J Med 1991;324: 865-871.

61 Halliday H: Surfactant, past, present and future. J Perinatol 2008;28(suppl 1):S47-S56.

62 Te Pas AB, Davis PG, Hooper SB, Morley CJ: From liquid to air: breathing after birth. J Pediatr 2008;152:607-611.

63 Grossman G, Nilsson R, Robertson B: Scanning electron microscopy of epithelial lesions induced by artificial ventilation of the immature neonatal lung; the prophylactic effect of surfactant replacement. Eur J Pediatr 1986;145:361-367.

-64 Hillman NH, Moss TJM, Kallapur SH, Bachurski C, Pillow JJ, Polglase GR, Nitsos I, Kramer BW, Jobe AH: Brief, large tidal volume ventilation initiates lung injury and a systemic response in fetal sheep. Am J Respir Crit Care Med 2007;176:575-581.
65 Wilson MR, Choudhury S, Goddard ME, O'Dea KP, Nicholson AG, Takata M: High tidal volume upregulates intrapulmonary cytokines in an in vivo mouse model of ventilatory-induced lung injury. J Appl Physiol 2003;95:1385-1393.

66 Speer CP: Inflammation and bronchopulmonary dysplasia: a continuing story. Semin Fetal Neonatal Med 2006;11:354-362.

67 Vento G, Capoluongo E, Matassa PG, Vendettuoli V, Vaccarella C, Frezza S, Zuppi C, Romagnoli C, Ameglio F: Serum levels of seven cytokines in premature ventilated newborns: correlations with old and new forms of bronchopulmonary dysplasia. Intensive Care Med 2006;32:723-730.

68 D'Alquen D, Kramer BW, Seidenspinner S, Marx A, Berq D, Groneck P, Speer CP: Activation of umbilical cord endothelial cells and fetal inflammatory response in preterm infants with chorioamnionitis and funisitis. Pediatr Res 2005;57:263-269.

69 Belperio JA, Keane MP, Burdick MD, Londhe V, Xue YY, Li K, Phillips RJ, Strieter RM: Critical role for CXCR2 and CXCR2 ligands during the pathogenesis of ventilator-induced lung injury. J Clin Invest 2002;110: 1703-1716

70 Tremblay L, Valenza F, Ribeiro SP, Li J, Slutsky AS: Injurious ventilatory strategies increase cytokines and c-fos $\mathrm{m}$-RNA expression in an isolated rat lung model. J Clin Invest 1997;99:944-952.

-71 Tremblay LN, Miatto D, Hamid Q, Govindarajan A, Slutsky AS: Injurious ventilation induces widespread pulmonary epithelial expression of tumor necrosis factor-alpha and interleukin-6 messenger RNA. Crit Care Med 2002;30:1693-1700.

72 Nwariaku FE, Rothenbach P, Liu Z, Zhu X, Turnage RH, Terada LS: Rho inhibition decreases TNF-induced endothelial MAPK activation and monolayer permeability. J Appl Physiol 2003;95:1889-1895.

73 Petrache I, Birukova A, Ramirez SI, Garcia JG, Verin AD: The role of the microtubules in tumor necrosis factor-alpha-induced endothelial cell permeability. Am J Respir Cell Mol Biol 2003;28:574-581.

74 Braun C, Hamacher J, Morel DR, Wendel A, Lucas R: Dichotomal role of TNF in experimental pulmonary edema reabsorption. J Immunol 2005; 175:3402-3408.

75 Gregory GA, Kitterman JA, Phibbs RH, Tooley WA, Hamilton WK: Treatment of the idiopathic respiratory distress system with continuous positive airway pressure. N Engl J Med 1971;284:1333-1340.

76 Halamek LP, Morley C: Continuous positive airway pressure during neonatal resuscitation. Clin Perinatol 2006;33:83-89.

77 Owen LS, Morley CJ, Davis PG: Neonatal nasal positive pressure ventilation: what do we know in 2007? Arch Dis Child Fetal Neonatal Ed 2007;92:F414-F418. 
78 Morley CJ, Davis PG: Continuous positive airway pressure: scientific and clinical rationale. Curr Opin Pediatr 2008;20:119-124.

79 Lundstrom K, Griesen G: Early treatment with nasal CPAP. Acta Paediatr 1993;82: 856-862.

80 Polin RA, Sahni R: Newer experience with CPAP. Semin Neonatol 2002;7:379-389.

-81 Ambalavanalan N, Carlo WA: Ventilatory strategies in the prevention and management of bronchopulmonary dysplasia. Semin Perinatol 2006;30:192-199.

82 Vanpée M, Walfridsson-Schultz U, Katz-Salamon M, Zupancic JAF, Pursley DW: Resuscitation and ventilation strategies for extremely preterm infants: a comparison study between two neonatal centers in Boston and Stockholm. Acta Paediatr 2007;96:10-16.

83 Te Pas AB, Spaans VM, Rijken M, Morley CJ, Walther FJ: Early nasal continuous positive airway pressure and low threshold for intubation in very preterm infants. Acta Paediatr 2008, May 14. Epub ahead of print.

84 Finer NN: Nasal continuous positive airway pressure does not reduce rate of death or bronchopulmonary dysplasia in preterm infants. J Pediatr 2008; 153:145.

85 Kirschbaum TH: The oxygen capacity of fetal hemoglobin. Am J Obstet Gynecol 1964; 88:823-827.

86 Dildy GA, van den Berg PP, Katz M, Clark SL, Jongsma HW, Nijhuis JG, Loucks CA: Intrapartum fetal pulse oximetry: fetal oxygen saturation trends during labor and relation to delivery outcome. Am J Obstet Gynecol 1994;171:679-684.

87 Kirschbaum TH, DeHaven JC, Shapiro N, Assali NS: Oxyhemoglobin dissociation characteristics of human and sheep maternal and fetal blood. Am J Obstet Gynecol 1966; 96:741-759.

88 Kirschbaum TH: Variability of magnitude of the Bohr effect in human fetal blood. J Appl Physiol 1963;18:729-733.

-89 Nijland R, Jongsma HW, Nijhuis JG, van den Berg PP, Oeseburg B: Arterial oxygen saturation in relation to metabolic acidosis in fetal lambs. Am J Obstet Gynecol 1995;172:810819.

-90 Bard H, Teasdale F: Red cell oxygen affinity, hemoglobin type, 2,3-diphospho-glycerate, and $\mathrm{pH}$ as a function of fetal development. Pediatrics 1979;64:483-487.

-91 Orzalesi MM, Hay WW: The regulation of oxygen affinity of fetal blood. I. In vitro experiments and results in normal infants. $\mathrm{Pe}$ diatrics 1971;48:857-864.

-92 House JT, Schultetus RR, Gravenstein N: Continuous neonatal evaluation in the delivery room by pulse oximetry. J Clin Monit 1987;3:96-100.

93 Rabi Y, Yee W, Chen SY, Singhal N: Oxygen saturation trends immediately after birth. J Pediatr 2006;148:590-594.
-94 Kamlin CO, O’Donnell CP, Davis PG, Morley CJ: Oxygen saturation in healthy infants immediately after birth. J Pediatr 2006;148: 585-589.

-95 Mariani G, Dik PB, Ezquer A, Aguirre A, Esteban ML, Perez C, Fernandez Jonusas S, Fustiñana C: Pre-ductal and post-ductal $\mathrm{O}_{2}$ saturation in healthy term neonates after birth. J Pediatr 2007;150:418-421.

-96 Saugstad OD: Oxygen saturations immediately after birth. J Pediatr 2006;148:569570.

$\$ 97$ Pallardo FV, Sastre J, Asensi M, Rodrigo F, Estrela JM, Viña J: Physiological changes in glutathione metabolism and newborn rat liver. Biochem J 1991;274:891-893.

-98 Sastre J, Asensi M, Rodrigo F, Pallardo FV, Vento M, Viña J: Antioxidant administration to the mother prevents oxidative stress associated with birth in the neonatal rat. Life Sci 1994;54:2055-2059.

99 Buonocore G, Perrone S, Longini M, Vezzosi P, Marzocchi B, Paffetti P, Bracci R: Oxidative stress in preterm neonates at birth and on the seventh day of life. Pediatr Res 2002;52:46-49.

100 Kumar A, Paniraghi I, Basu S, Dash D: Urinary malondialdehyde levels in newborns following delivery room resuscitation. Neonatology 2008;94:96-99.

101 Safiulina VF, Afzalov R, Khiroug L, Cherubini E, Giniatullin R: Reactive oxygen species mediate the potentiating effects of ATP on GABAergic synaptic transmission in the immature hippocampus. J Biol Chem 2006; 281:23464-23470.

102 Martin JA, Pereda J, Martinez-Lopez I, Escrig R, Miralles V, Pallardo FV, Viña JR, Vento M, Viña J, Sastre J: Oxidative Stress as a signal to up-regulate gamma cystathionase in the fetal-to-neonatal transition in rats. Cell Mol Biol (Noisy-le-grand) 2007; 53(suppl):OL1010-OL1017.

103 Vento M, Sastre J, Asensi MA, Viña J: Room-air resuscitation causes less damage to heart and kidney than $100 \%$ oxygen. Am J Respir Crit Care Med 2005;172:13931398.

104 Comporti M, Signorini C, Leoncini S, Buonocore G, Rossi V, Ciccoli L: Plasma F2isoprostanes are elevated in newborns and inversely correlated to gestational age. Free Radic Biol Med 2004;37:724-732.

105 Saugstad OD: Update on oxygen radical disease in neonatology. Curr Opin Obstet Gynecol 2001;13:147-153.

-106 Saugstad OD: Optimal oxygenation at birth and in the neonatal period. Neonatology 2007;91:319-322.

107 Sola A, Rogido MR, Deulofeut R: Oxygen as a neonatal health hazard: call for a détente in clinical practice. Acta Paediatr 2007;96: 801-812.

108 Wang CL, Anderson C, Leone TA, Rich W, Govindaswami B, Finer NN: Resuscitation of preterm neonates using room air or $100 \%$ oxygen. Pediatrics 2008;12:1083-1089.
109 Escrig R, Arruza L, Izquierdo I, Villar G, Saenz P, Gimeno A, Moro M, Vento M: Achievement of target saturation in extremely low gestational age neonates resuscitated with different oxygen concentrations: a prospective randomized clinical trial. Pediatrics 2008;121:875-881.

110 Rabi Y, Nettel-Aguirre A, Singhal N: Room Air versus Oxygen Administration during Resuscitation of Preterm Infants (ROAR Study). Pediatric Academic Societies 2008.

111 American Heart Association AAP: 2005 American Heart Association (AHA) guidelines for cardiopulmonary resuscitation (CPR) and emergency cardiovascular care (ECC) of pediatric and neonatal patients: neonatal resuscitation guidelines. Pediatrics 2006;117:e1029-e1038.

112 International Liaison Committee on Resuscitation: The International Liaison Committee on Resuscitation (ILCOR) consensus on science with treatment recommendations for pediatric and neonatal patients: neonatal resuscitation. Pediatrics 2006;117:e978-e988.

113 Deulofeut R, Critz A, Adams-Chapman I, Sola A: Avoiding hyperoxia in infants < or $=1250 \mathrm{~g}$ is associated with improved short- and long-term outcomes. J Perinatol 2006;26:700-705

114 Vento M, Asensi M, Sastre J, García-Sala F, Pallardó FV, Viña J: Resuscitation with room air instead of $100 \%$ oxygen prevents oxidative stress in moderately asphyxiated term neonates. Pediatrics 2001;107:642647.

115 Borke WB, Munkeby BH, Halvorsen B, Bjornland $\mathrm{K}$, Tunheim $\mathrm{SH}$, Borge GI, Thaulow E, Saugstad OD: Increased myocardial matrix metalloproteinases in hypoxic newborn pigs during resuscitation: effects of oxygen and carbon dioxide. Eur J Clin Invest 2004;34:459-466.

116 Lakshminrusimha S, Russell JA, Steinhorn RH, Ryan RM, Gugino SF, Morin FC 3rd, Swartz DD, Kumar VH: Pulmonary arterial contractility in neonatal lambs increases with $100 \%$ oxygen resuscitation. Pediatr Res 2006;59:137-141.

117 Munkeby BH, Børke WB, Bjørnland K, Sikkeland LI, Borge GI, Halvorsen B, Saugstad OD: Resuscitation with $100 \% \mathrm{O}_{2}$ increases cerebral injury in hypoxemic piglets. Pediatr Res 2004;56:783-790.

$>118$ Haase E, Bigam DL, Nakonechny QB, Jewell LD, Korbutt G, Cheung PY: Resuscitation with $100 \%$ oxygen causes intestinal glutathione oxidation and reoxygenation injury in asphyxiated newborn piglets. Ann Surg 2004;240:364-373.

119 Cheung PY, Obaid L, Emara M, Brierley Y, Johnson ST, Chan GS, Jewell L, Korbutt G, Bigam DL: Cardio-renal recovery of hypoxic newborn pigs after 18, 21 and $100 \%$ reoxygenation. Intensive Care Med 2008;34: 1114-1121. 
120 Chapados I, Chik C, Cheung PY: Higher cortisol response to adrenocorticotrophin (ACTH) stimulation in hypoxic newborn piglets resuscitated with $21 \%$ than $100 \%$ oxygen. E-PAS 2007;7932:17.

121 Cheung PY, Stevens JP, Haase E, Stang L, Bigam DL, Etches W, Radomski MW: Platelet dysfunction in asphyxiated newborn piglets resuscitated with 21 and $100 \%$ oxygen. Pediatr Res 2006;59:636-640.

- 122 Naumburg E, Bellocco R, Cnattingius S, Jonzon A, Ekbom A: Supplementary oxygen and risk of childhood lymphatic leukaemia. Acta Paediatr 2002;91:1328-1333.

- 123 Spector LG, Klebanoff MA, Feusner JH, Georgieff MK, Ross JA: Childhood cancer following neonatal oxygen supplementation. J Pediatr 2005;147:27-31.

124 Kuisma M, Boyd J, Voipio V, Alaspää A, Roine RO, Rosenberg P: Comparison of 30 and the $100 \%$ inspired oxygen concentrations during early post-resuscitation period: a randomised controlled pilot study. Resuscitation 2006;69:199-206.

- 125 Presti AL, Kishkurno SV, Slinko SK, Randis TM, Ratner VI, Polin RA, Ten VS: Reoxygenation with $100 \%$ oxygen versus room air: late neuroanatomical and neurofunctional outcome in neonatal mice with hypoxic-ischemic brain injury. Pediatr Res 2006;60:55-59.

126 Watkinson M: Temperature control of premature infants in the delivery room. Clin Perinatol 2006;33:43-53.

127 World Health Organization: Thermal control of the newborn: a practical guide. Maternal health and safe motherhood programme (WHO/FHE/MSM/93.2). Geneva (Switzerland), World Health Organization, 1993.

128 Hammarlund K, Nilsson GE, Oberg PA, et al: Transepidermal water loss in newborn infants. V. Evaporation from the skin and heat exchange during the first hours of life. Acta Paediatr Scand 1980;69:385-392.

129 Hammarlund K, Sedin G: Transepidermal water loss in newborn infants. III. Relation to gestational age. Acta Paediatr Scand 1979;68:795-801.

130 Hammarlund K, Sedin G: Transepidermal water loss in newborn infants. VI. Heat exchange with the environment in relation to gestational age. Acta Paediatr Scand 1982; 71:191-196.

-131 Hammarlund K, Sedin G, Strömberg B: Transepidermal water loss in newborn infants. VIII. Relation to gestational age and post-natal age in appropriate and small for gestational age infants. Acta Paediatr Scand 1983;72:721-728.
132 Kjartansson S, Arsan S, Hammarlund K, Sjörs G, Sedin G: Water loss from the skin of term and preterm infants nursed under a radiant heater. Pediatr Res 1995;37:233238.

133 Sjörs G, Hammarlund K, Sedin G: Thermal balance in term and preterm newborn infants nursed in an incubator equipped with a radiant heat source. Acta Paediatr 1997; 86:403-409.

134 Doyle LW, Sinclair JC: Insensible water loss in newborn infants. Clin Perinatol 1982;9: 453-478.

135 Harned HS, Herrington RT, Ferreiro JI: The effects of immersion and temperature on respiration in newborn lambs. Pediatrics 1970;45:598-605.

136 Pomerance JJ, Madore C: Effect of temperature on survival of infants with RDS. Pediatr Res 1974;8:449-454.

137 Gandy GM, Adamsons K, Cunningham N: Thermal environment and acid-base homeostasis in human infants during the first few hours of life. J Clin Invest 1964;43:751758.

138 Oliver TK: Temperature regulation and heat production in the newborn. Pediatr Clin N Amer 1965;12:765-779.

139 Elliott RI, Mann TP: Neonatal cold injury due to accidental exposure to cold. Lancet 1957;272:229-234.

140 Laptook A, Jackson GL: Cold stress and hypoglycemia in the late preterm ('near-term') infant: impact on nursery admission. Semin Perinatol 2006;30:24-27.

141 Chadd MA, Gray OP: Hypothermia and coagulation defects in the newborn. Arch Dis Child 1972;47:819-821.

142 Laptook A, Salhab W, Bhaskar B: Admission temperature of low birth weight infants: predictors and associated morbidities. Pediatrics 2007;119:e643-e649.

143 Bligh J, Johnson KG: Glossary of term for thermal physiology. J Appl Physiol 1973;35: 941-961.

144 Silverman WA, Fertig JW, Berger P: The influence of the thermal environment upon the survival of newly born premature infants. Pediatrics 1958;22:876-886.

145 Laptook AR, Watkinson M: Temperature management in the delivery room. Semin Fetal Neonatal Med 2008, May 21. Epub ahead of print.

146 Leblanc MH: Relative efficacy of an incubator and an open warmer in producing thermoneutrality for the small premature infant. Pediatrics 1982;69:439-445.

147 Wheldon AE, Rutter N: The heat balance of small babies nursed in incubators and under radiant warmers. Early Hum Dev 1982; 6:131-143.

148 Baumgart S, Engle WD, Fox WW: Effect of heat shielding on convective and evaporative heat losses and on radiant heat transfer in premature infant. J Pediatr 1981;99:948956.
149 Baumgart S: Reduction of oxygen consumption, insensible water loss and radiant heat demand with use of a plastic blanket for low-birth-weight infants under radiant warmers. Pediatrics 1984;74:1022-1028.

150 Baumgart S, Fox WW, Polin RA: Physiologic implications of two different heat shields under radian warmers. J Pediatr 1982;100: 787-790.

151 Knauth A, Gordin M, McNelis W: Semipermeable polyurethane membrane as an artificial skin for the premature neonate. Pediatrics 1989;83:945-950.

152 LeBlanc MH: Thermoregulation: incubators, radiant warmers, artificial skins and body hoods. Clin Perinatol 1991;18:403422.

153 Vohra S, Frent G, Campbell V: Effect of polyethylene occlusive skin wrapping on heat loss in very low birth weight infants at delivery: a randomized trial. J Pediatr 1999; 134:547-551.

154 Lenclen R, Mazraani M, Jugie M: Use of a polyethylene bag: a way to improve the thermal environment of the premature newborn at the delivery room. Arch Pediatr 2002;9:238-244.

155 Newton T, Watkinson M: Preventing hypothermia at birth in preterm babies: at a cost of overheating some? Arch Dis Child Fetal Neonatal Ed 2003;88:F256-F263.

156 McCall EM, Alderdice FA, Halliday HL, Jenkins JG, Vohra S: Interventions to prevent hypothermia at birth in preterm and/ or low birth weight infants. Cochrane Database Syst Rev 2008, Jan 23; CD004210. Review.

157 Mercer JS: Current best evidence: a review of the literature on umbilical cord clamping. J Midwifery Womens Health 2001;46: 402-414.

158 Mercer JS, Skovgaard RL: Neonatal transitional physiology. J Perinat Neonatal Nurs 2002;15:56-75.

159 Pisacane A: Neonatal prevention of iron deficiency: placental transfusion is a cheap and physiological solution. BMJ 1996;312: 136-137.

160 Romano AM: Research summaries for normal birth. J Perinat Educ 2007;16:53-58.

161 Hutton EK, Hassan ES: Late versus early clamping of the umbilical cord in full-term neonates: Systematic review and metaanalysis of controlled trials. JAMA 2007; 297:1241-1252.

162 Rabe H, Reynolds F, Diaz-Rosello J: A systematic review and meta-analysis of a brief delay in clamping the umbilical cord of preterm infants. Neonatology 2008;93:138144. 